\title{
Exome sequencing in 38 patients with intracranial aneurysms and subarachnoid hemorrhage
}

\author{
Thomas Sauvigny ${ }^{1} \cdot$ Malik Alawi $^{2} \cdot$ Linda Krause $^{3} \cdot$ Sina Renner ${ }^{4} \cdot$ Michael Spohn $^{2,5,6}$. Alice Busch ${ }^{4} \cdot$ Verena Kolbe $^{4}$. \\ Janine Altmüller ${ }^{7} \cdot$ Britt-Sabina Löscher $^{8} \cdot$ Andre Franke $^{8} \cdot$ Christian Brockmann $^{9} \cdot$ Wolfgang Lieb $^{10}$.

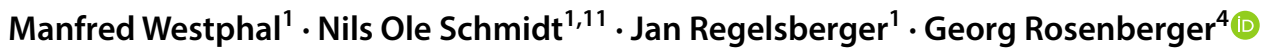

Received: 19 December 2019 / Revised: 8 April 2020 / Accepted: 24 April 2020 / Published online: 4 May 2020

(c) The Author(s) 2020

\begin{abstract}
Objective Genetic risk factors for unruptured intracranial aneurysms (UIA) and aneurysmal subarachnoid hemorrhage (aSAH) are poorly understood. We aimed to verify recently reported risk genes and to identify novel sequence variants involved in the etiology of UIA/aSAH.

Methods We performed exome sequencing (ES) in 35 unrelated individuals and 3 family members, each with a history of UIA and/or aSAH. We searched for sequence variants with minor allele frequency (MAF) $\leq 5 \%$ in the reported risk genes ADAMTS15, ANGPTL6, ARHGEF17, LOXL2, PCNT, RNF213, THSD1 and TMEM132B. To identify novel putative risk genes we looked for unknown $(\mathrm{MAF}=0)$ variants shared by the three relatives.

Results We identified 20 variants with MAF $\leq 5 \%$ in 18 individuals: 9 variants in PCNT (9 patients), 4 in $R N F 213$ (3 patients), 3 in THSDI (6 patients), 2 in ANGPTL6 (3 patients), 1 in ADAMTS15 (1 patient) and 1 in TMEM132B (1 patient). In the affected family, prioritization of shared sequence variants yielded five novel putative risk genes. Based on predicted pathogenicity of identified variants, population genetics data and a high functional relevance for vascular biology, EDIL3 was selected as top candidate and screened in additional 37 individuals with UIA and/or aSAH: a further very rare EDIL3 sequence variant in two unrelated sporadic patients was identified.

Conclusions Our data support a role of sequence variants in PCNT, RNF213 and THSD1 as susceptibility factors for cerebrovascular disease. The documented function in vascular wall integrity, the crucial localization of affected amino acids and gene/variant association tests suggest EDIL3 as a further valid candidate disease gene for UIA/aSAH.
\end{abstract}

Keywords Subarachnoid hemorrhage $\cdot$ Intracranial aneurysms $\cdot$ Disease gene identification $\cdot$ Exome sequencing $\cdot$ EDIL3

\section{Introduction}

Aneurysmal subarachnoid hemorrhage (aSAH) affects approximately 500,000 individuals per year worldwide and, despite immense medical attempts, is associated with high mortality [1]. The risk/prevalence of intracranial aneurysms (IA) in the general population is even higher and estimated at around 3\% [2]. Besides life-style and medical risk factors (e.g. smoking, hypertension), the risk for IA and aSAH is

Electronic supplementary material The online version of this article (https://doi.org/10.1007/s00415-020-09865-6) contains supplementary material, which is available to authorized users.

Georg Rosenberger

rosenberger@uke.de

Extended author information available on the last page of the article increased among patient's family members. However, the genetic background of the disease is still poorly understood. Although large genome or exome wide association studies (GWAS or EWAS) identified several risk loci, valid disease genes have not been established [3]. In addition to GWAS providing associations between genomic regions and a disease, novel advanced approaches using exome sequencing (ES) promise to detect causal relations. Indeed, recent studies applied ES in families affected with IA/SAH and identified alterations in ANGPTL6 (angiopoietin-like 6), RNF213 (ring finger protein 213), THSD1 (thrombospondin type 1 domain containing protein 1), ARHGEF17 (Rho guanine nucleotide exchange factor 17) and PCNT (pericentrin) as genetic risk factors for this disease [4-8]. Other family-based ES studies reported on various candidate disease variants and genes including ADAMTS15, LOXL2 and TMEM132B, 
and emphasize the need of validation of their presented data [9-11]. The a.m. studies on genetic risk factors for IA/SAH differ in the resulting strength of evidence (for details see Supplementary Introduction).

Clearly, the significance of ES data highly depends on thorough clinical phenotypic characterization because, in addition to heritable conditions, IA/SAH is also associated with acquired risk factors [12]. Since a genetic background may well be of importance and significance for both, unruptured intracranial aneurysms (UIA) and aSAH [13, 14], we established and describe here a cohort comprising individuals with a familial history of UIA and/or aSAH and substantially affected sporadic patients with UIA and/or aSAH. We performed ES in 38 patients to validate already reported candidate genes for IA/SAH on the one hand, and to identify novel susceptibility genes on the other. We completed our genetic screen by sequencing the top candidate gene in the entire patient cohort.

\section{Methods}

\section{Study cohort}

Individuals of Northwestern German descent (genetically belonging to the group of non-Finnish, Northwestern Europeans) were recruited in the Interdisciplinary Neurovascular Center of the University Medical Center Hamburg-Eppendorf, Hamburg, Germany; approximately 70 patients with aSAH and 200 patients with intracranial aneurysms in total are treated there per year. Inclusion-exclusion criteria were as follows: (i) Only individuals with a family history of UIA and/or aSAH and substantially affected sporadic patients with $\geq 2$ UIA or $\geq 1$ UIA and aSAH were included. To that, we selected patients based on age, number of aneurysms and family history, resulting in a collective of relatively young patients with an increased number of aneurysms and family history above average compared to data provided in the literature (Table 1) $[15,16]$. Experienced physicians assessed the patients; familial history, clinical appearance, primary risk conditions (e.g. hypertension) and life-style risk factors (e.g. smoking) were recorded (Table 1). Missing clinical data of patients previously treated in a different institution were gathered as far as possible. Phenotype definitions following the FIA study protocol [9]: "UIA and/or aSAH" (individuals having a documented UIA based on intra-arterial angiogram or operative report; individuals having an aSAH documented in medical records based on CT/MRI-scan, intra-arterial angiogram or operative report); "probable aSAH" (aSAH was stated in the medical history with supporting documentation such as severe headache or altered level of consciousness). (ii) Informed consents for blood collection, DNA storage and genetic analyses were obtained from all study participants. (iii) Patients with a familial or personal history of disorders associated with IA (i.e. polycystic kidney disease, Ehlers-Danlos syndrome, Loeys-Dietz syndrome and Marfan syndrome) were excluded based on clinical findings. In total, we screened 101 individuals, of which 75 met the described inclusion criteria. To assess the putative risk of rupture in patients with UIA in comparison to those with a proven aneurysmal bleeding, we calculated the PHASES score (Table 1) [17]. In patients with multiple UIAs, the score was calculated for each aneurysm site and size, and the highest score was documented (Table 1). In the aSAH group, the score for the ruptured aneurysm was calculated retrospectively (Table 1). Finally, we assessed clinical characteristics for following subgroups (Table 1): exome sequenced individuals (ES IND), individuals with positive family history (FAM IND) and substantially affected sporadic individuals (SPO IND).

\section{Exome sequencing, variant calling, filtering strategies, variant prioritization and pathogenicity assignment}

Exome sequencing (ES) is a genomic technique for sequencing all coding regions (=exome) of a genome: after capturing only the subset of DNA that encodes proteins, the exome is sequenced using a high-throughput DNA sequencing technology. We performed ES in 35 unrelated individuals and 3 affected members of a family. Selection criteria and constraints of subjects for exome and Sanger sequencing are explained in detail in Supplementary Methods and Table S1. Although genome-wide association studies (GWAS) that focus on the identification of common variants (minor allele frequency, MAF $>5 \%$ ) revealed a large number of risk loci associated with IA/SAH, the accounted heritability in these loci was low [18]. The prevalence of IA is reported to be approximately 5\% in average [2]; for genetic disorders the phenotype prevalence and penetrance should be used to define the allele frequency cutoff [19]. Therefore, for the validation of reported UIA/SAH risk genes, we screened for low-frequency (MAF $>1$ to $5 \%$ ), rare (MAF $>0.1$ to $1 \%$ ), very rare $(\mathrm{MAF} \leq 0.1 \%)$ and unknown variants $(\mathrm{MAF}=0)$ in these genes [20,21], thereby including those variants with strong, intermediate as well as moderate effect size and penetrance [22]. For the identification of novel susceptibility genes in the family-based approach we searched for unknown variants (MAF $=0$; with anticipated significant effect size/penetrance) shared by the affected family members. Subsequent variant prioritization, the top familial candidate disease gene was examined in the remaining 37 patients from our cohort.

Detailed information on exome sequencing, variant calling, filtering strategy, variant prioritization, pathogenicity assignment, variant classification, mutation analysis, 
Table 1 Clinical characteristics

\begin{tabular}{|c|c|c|c|c|c|c|}
\hline Characteristics & $\begin{array}{l}\text { All }(n=75) \\
\text { Mean } \pm \text { SD (range) }\end{array}$ & $\begin{array}{l}\text { aSAH }(N=48) \\
\text { Mean } \pm \text { SD (range) }\end{array}$ & $\begin{array}{l}\text { UIA }(N=27) \\
\text { Mean } \pm \text { SD (range) }\end{array}$ & $\begin{array}{l}\text { ES IND }(n=35) \\
\text { Mean } \pm \text { SD (range) }\end{array}$ & $\begin{array}{l}\text { FAM IND }(n=30) \\
\text { Mean } \pm \text { SD (range) }\end{array}$ & $\begin{array}{l}\text { SPO IND }(N=45) \\
\text { Mean } \pm \text { SD (range) }\end{array}$ \\
\hline Age at SAH (years) & & $46.9 \pm 12.1(9-71)$ & & & & \\
\hline IA (count) & $1.96 \pm 1.40(1-6)$ & $1.8 \pm 1.3(0-6)$ & $2.3 \pm 1.6(1-6)$ & $2.23 \pm 1.57(1-6)$ & $1.80 \pm 1.27(1-6)$ & $2.07 \pm 1.48(1-6)$ \\
\hline $\begin{array}{l}\text { Aneurysm diameter } \\
(\mathrm{mm})\end{array}$ & $7.1 \pm 6.6(1.5-47.0)$ & $5.7 \pm 2.6(1.5-13.0)$ & $\begin{array}{l}9.6 \pm 910.2 \\
\quad(2.0-47.0)\end{array}$ & $\begin{array}{l}5.76 \pm 3.22 \\
\quad(1.5-47.0)\end{array}$ & $\begin{array}{l}6.75 \pm 5.95 \\
\quad(2.0-30.0)\end{array}$ & $\begin{array}{l}7.35 \pm 7.07 \\
\quad(1.5-47.0)\end{array}$ \\
\hline Phases score & $4.8(0-13)$ & $4.7(0-12)$ & $5.0(0-13)$ & $4.8(0-13)$ & $4.5(0-13)$ & $5.0(0-12)$ \\
\hline Hunt and hess grade & & $2.3(1-5)$ & & & & \\
\hline WFNS grade & & $1.9(1-5)$ & & & & \\
\hline Fisher score & & $3.4(1-4)$ & & & & \\
\hline $\begin{array}{l}\text { Outcome at discharge } \\
\text { (EGOS) }\end{array}$ & & $4.9(1-8)$ & & & & \\
\hline LAO (months) & & $83 \pm 298(2-1343)$ & & & & \\
\hline \multirow[t]{2}{*}{$\begin{array}{l}\text { Outcome LAO } \\
\text { (MRS) }\end{array}$} & & $1.3(0-6)$ & & & & \\
\hline & Count (\%) & Count (\%) & Count (\%) & Count (\%) & Count (\%) & Count (\%) \\
\hline \multicolumn{7}{|l|}{ Sex } \\
\hline Female & $53(70.7)$ & $35(72.9)$ & $18(66.7)$ & $26(74.3)$ & $22(73.3)$ & $31(68.9)$ \\
\hline Male & $22(29.3)$ & $13(17.3)$ & $9(33.3)$ & $9(25.7)$ & $8(26.7)$ & $14(31.1)$ \\
\hline \multicolumn{7}{|l|}{ Aneurysm location $^{a}$} \\
\hline Anterior circulation & $56(80.0)$ & $34(77.3)$ & $22(84.6)$ & $25(75.8)$ & $22(81.5)$ & $34(79.1)$ \\
\hline Posterior circulation & $11(15.7)$ & $10(22.7)$ & $1(3.8)$ & $7(21.2)$ & $5(18.5)$ & $6(14.0)$ \\
\hline Both & $3(4.3)$ & - & $3(11.5)$ & $1(3.0)$ & - & $3(7.0)$ \\
\hline Unknown & 5 & & & 2 & 3 & 2 \\
\hline \multicolumn{7}{|l|}{ Family history } \\
\hline Yes & $30(40)$ & $13(27.1)$ & $17(63.0)$ & $14(60.0)$ & $30(100.0)$ & $0(0.0)$ \\
\hline No & $45(60)$ & $35(72.9)$ & $10(37.0)$ & $21(40.0)$ & $0(0.0)$ & $45(100.0)$ \\
\hline \multicolumn{7}{|l|}{ Vascular risk factors } \\
\hline Hypertension & $27(36.5)$ & $13(27.7)$ & $14(51.9)$ & $13(37.1)$ & $12(41.4)$ & $15(33.3)$ \\
\hline Diabetes & $3(4.1)$ & $1(2.1)$ & $2(7.4)$ & $1(2.9)$ & $1(3.4)$ & $2(4.4)$. \\
\hline Hyperlipidemia & $6(8.1)$ & $3(6.4)$ & $3(11.1)$ & 4 (11.4) & $3(10.3)$ & $3(6.7)$ \\
\hline Prev. cardiovas. disease & $4(5.5)$ & $2(4.3)$ & $2(7.4)$ & $2(5.7)$ & $1(3.4)$ & $3(6.8)$ \\
\hline Prev. neurol. disease & $12(16.4)$ & $9(19.6)$ & $3(11.1)$ & $9(25.7)$ & $1(3.4)$ & $7(15.9)$ \\
\hline Ever smoker & $41(56.2)$ & $28(59.6)$ & $13(50.0)$ & $20(57.1)$ & $18(62.1)$ & $23(52.3)$ \\
\hline Alcohol & $2(2.7)$ & $2(4.3)$ & $0(0.0)$ & $1(2.9)$ & $0(0.0)$ & $2(4.4)$ \\
\hline \multicolumn{7}{|l|}{ Treatment } \\
\hline Endovascular & $34(47.2)$ & $29(63.0)$ & $5(47.2)$ & $12(36.4)$ & $8(29.6)$ & $26(57.8)$ \\
\hline Surgical & $27(37.5)$ & $13(28.3)$ & $14(53.8)$ & $15(45.5)$ & $12(44.4)$ & $15(33.3)$ \\
\hline Both & $11(15.3)$ & $4(8.7)$ & $7(26.9)$ & $6(18.2)$ & $7(25.9)$ & $4(8.9)$ \\
\hline No & - & - & - & - & - & - \\
\hline Unknown & 3 & & & 2 & 3 & \\
\hline \multicolumn{7}{|l|}{ DCI } \\
\hline Yes & & $16(38.1)$ & & & & \\
\hline No & & $26(61.9)$ & & & & \\
\hline Unknown & & 6 & & & & \\
\hline
\end{tabular}

$S D$ standard deviation, $a S A H$ aneurysmal subarachnoid hemorrhage, UIA unruptured intracranial aneurysm, ES IND exome sequenced individuals, FAM IND individuals with positive family history, SPO IND substantially affected sporadic individuals, $I A$ intracranial aneurysm, $B M I$ body mass index, GCS Glasgow Coma Scale, WFNS World Federation of Neurosurgical Societies, EGOS Extended Glasgow Outcome Scale, LAO last available outcome, MRS Modified Rankin Scale, DCI delayed cerebral injury

${ }^{a}$ Only the ruptured aneurysm was reported in the aSAH group 
presentation of clinical data, statistical analysis (gene association tests), molecular modeling as well as databases and repositories is outlined in Supplementary Methods.

\section{Results}

\section{Clinical characteristics}

Our study cohort comprises 75 subjects (53 female; 70.7\%) including 48 individuals $(64.0 \%)$ with aneurysmal subarachnoid bleeding (aSAH group, Table 1) and 27 patients $(36.0 \%)$ with UIA (UIA group, Table 1). 31 patients (41.3\%) showed multiple IA (including ruptured and unruptured), the mean count of aneurysms was 2.3 in the UIA group and 1.8 in the aSAH group. In the latter group, 5 patients $(10.4 \%)$ suffered from a previous aSAH. In addition to UIA and/ or aSAH, three patients $(4.0 \%)$ had an aortic aneurysm. 30 individuals $(40.0 \%)$ reported a family history of IA and/or SAH. The mean PHASES score was 4.8. Clinical data are summarized in Table 1. Taken together, this cohort consists of individuals with a family history of UIA and/or aSAH and substantially affected patients with UIA and/or aSAH.

\section{Genetic analysis of reported risk genes}

38 patients underwent ES. The presence of possibly pathogenic variants in known disease genes for vascular/connective tissue disorders was excluded (details are given in Supplementary Methods and Table S2). Subsequently, exome data were analyzed for variants in the reported risk genes ADAMTS15, ANGPTL6, ARHGEF17, LOXL2, PCNT, RNF213, THSD1 and TMEM132B. In total we found 20, exclusively heterozygous missense variants with $\mathrm{MAF} \leq 0.05$ (5\%) in 6 genes (Table 2): 9 PCNT variants were identified in 9 patients, 4 RNF213 variants in 3 patients, 3 THSDI variants in 6 patients, 2 ANGPTL6 variants in 3 patients, and 1 variant in ADAMTS15 and TMEM132B in 1 patient each. No variants were detected in ARHGEF17 and LOXL2. According to ACMG/AMP guidelines [23], we defined 17 variants of uncertain significance (VUS) and 3 likely benign variants (LBV) (Table 2). Details on criteria for classifying variants are given in Table 2 and in Supplementary Methods. All detected variants were annotated in dbSNP (www. ncbi.nlm.nih.gov/SNP/) and gnomAD [24]; we did not find undescribed variants in the reported risk genes.

In total, 18 unrelated individuals carry variants in reported risk genes (Table 2). Eleven patients (IA24, IA49, IA57, IA59, IA64, IA72, IA75, IA76, IA83, IA84 and IA90) had one variant. Seven patients had concomitant variants: IA63 and IA85 had two variants in PCNT; for IA63 these variants were in trans. IA79 showed one variant each in $P C N T$ and $R N F 213$, IA54 in PCNT and THSD1, IA61 in ANGPTL6 and $R N F 213$, and IA17 in THSD1 and TMEM132B. Notably, the number of variants had no impact on clinical manifestation. Finally, we detected 3 variants ( 1 in ANGPTL6 and 2 in $R N F 213$ ) in patient IA78 (Table 2). Within the analyzed patient cohort, we found 4 recurrent VUS (Table 2): ANGPTL6 c. $287 \mathrm{~A}>\mathrm{G}$ p.(Leu96Pro), PCNT c.4354G $>$ A p.(Gly1452Arg) and $P C N T$ c.7652C $>$ T p.(Ala2551Val) in 2 patients each; and THSD1 c.871C $>$ T p.(Glu291Lys) in 4 patients. In case of DNA of further affected and unaffected family members was available, cosegregation with disease was checked. The $P C N T$ c.6739C $>$ T p.(His2247Tyr) variant in IA24 did not cosegregate with the disease in the family (Figure S1A), indicating that this variant is not pathogenic. THSD1 c.871C $>$ T p.(Glu291Lys) in IA90, however, was also identified in 2 affected siblings (Figure S1A), thereby supporting a clinical relevance for this variant.

\section{Determination of novel putative risk genes}

We performed ES in a family with three affected family members (Fig. 1a). The three siblings share no reportable sequence alteration in known genes associated with vascular/connective tissue disorders (Table S2). From ES data, we extracted potentially pathogenic sequence variants by bioinformatics stratification, biological filter steps and variant prioritization (details are outlined in Supplementary Methods). Briefly, our filtering steps retained homozygous and heterozygous variants if they (i) were present in all affected family members; (ii) were listed neither in the database gnomAD [24], nor in a combined exome dataset of population-based controls from PopGen $[25,26]$ and of control samples collected in the Institute of Clinical Molecular Biology in Kiel (IKMB-controls); (iii) were predicted to be synonymous variants, missense variants, nonsense variants, frameshift indels or intronic alterations at exon-intron boundaries ranging from -2 to +2 ; and (iv) were predicted to be damaging by CADD, REVEL, M-CAP and/or ClinPred; missense variants with less than two scores above the respective pathogenicity thresholds were excluded; nonsense variants and indels causing premature termination were retained if CADD score was above recommended pathogenicity threshold; synonymous variants were retained if consequences on splicing was suggested by $>1$ in silico predictor (Table 3). This stringent filtering pipeline revealed five candidate risk variants for UIA/aSAH in NEK4, EDIL3, EDNRB, DNAH9 and GGA3 in this family (Table 3). We classified these variants according to ACMG/AMP guidelines [23], and we defined five VUS (Table 3) including EDIL3 c.383G >A p.(Cys128Tyr) (Fig. 1b).

Based on pathogenicity predictions and a strong functional relevance of EDIL3 protein (see "Discussion", Supplementary Methods and Table S3), we analyzed EDIL3 coding region in available exome data and by Sanger 


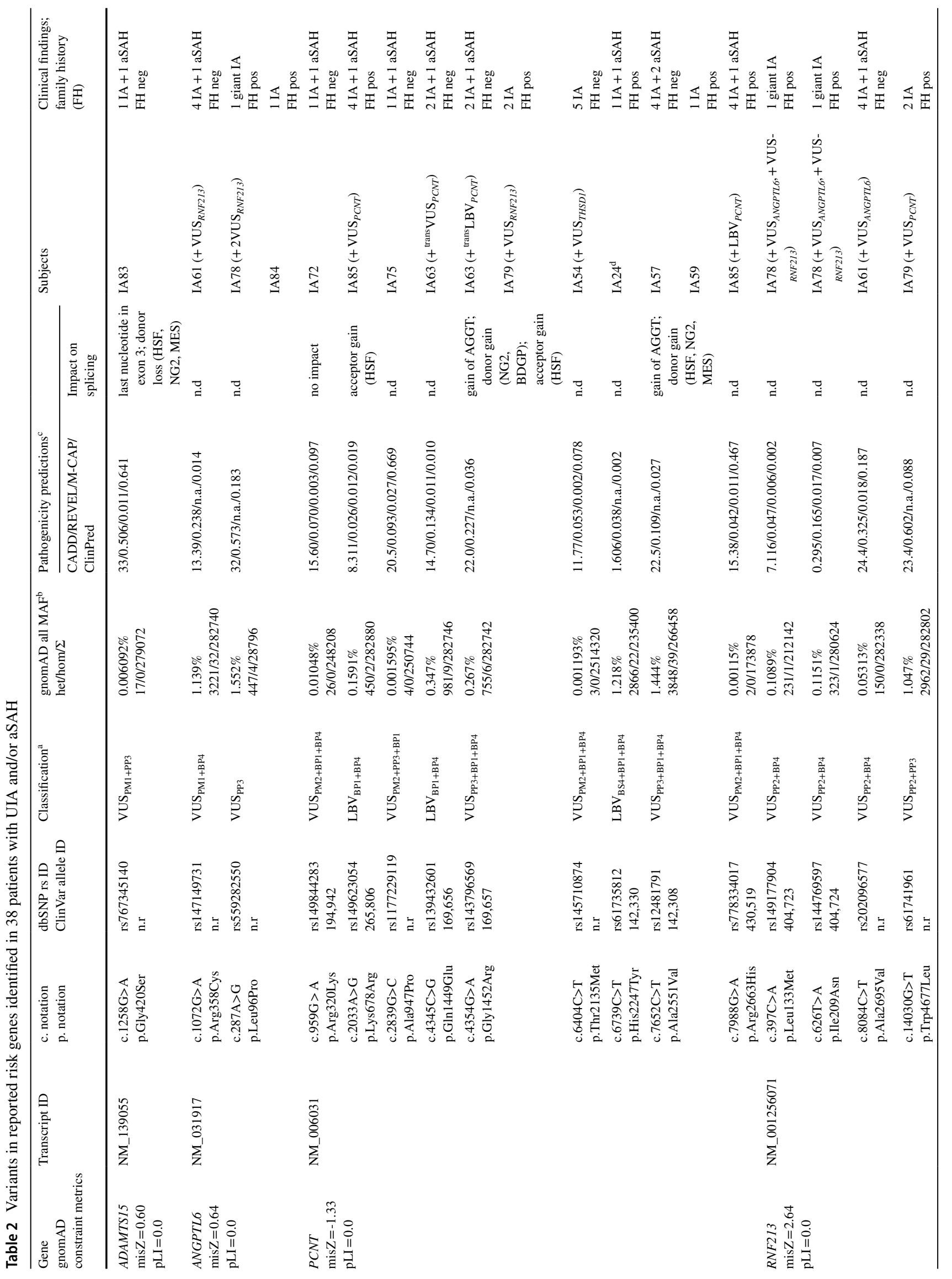




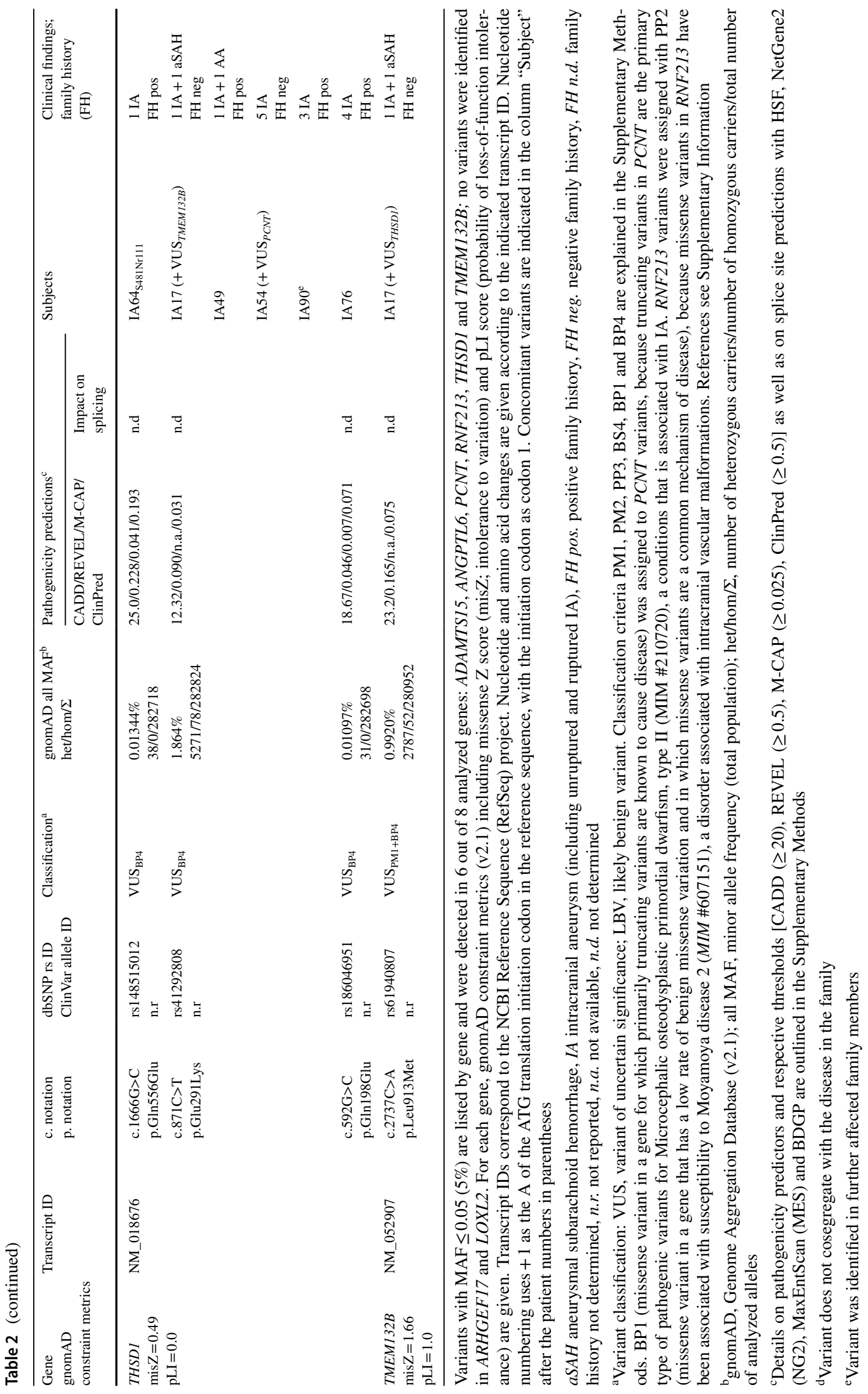


sequencing in 35 and 37 patients, respectively. We detected a very rare variant classified to be a $\mathrm{VUS}_{\mathrm{PM} 2+\mathrm{PP} 3}$ in EDIL3 (c.1159A >C, p.(Lys387Gln)) (Fig. 1b) in two further unrelated patients (IA10 and IA13) both with no reported family history. IA10 showed two intracranial, one carotid and two aortic aneurysms; IA13 had two intracranial aneurysms and aSAH at the age of 35 years. The allele frequency of EDIL3 c.1159A $>$ C p.(Lys387Gln) is 0.000131 in gnomAD and similarly small with 0.000101 within 5814 healthy control individuals from the German population-based datasets IKMB-controls and PopGen [24-26]. Notably, gnomAD may contain data from cerebrovascular patients and thus the presence of specific variants does not exclude pathogenicity. The variant is predicted to be deleterious by three ensemble pathogenicity classifiers including CADD (score 24.5), REVEL (score 0.723) and M-CAP (score 0.266). We also identified additional variants with $\mathrm{MAF} \leq 0.05$ in the remaining four candidate risk genes in available exomes of our cohort. However, relatively high MAFs and/or low pathogenicity prediction scores do not support a role for $N E K 4, E D N R B, D N A H 9$ and GGA3 variants in the etiology of UIA/aSAH (Table S4).

To test the association of unknown and very rare EDIL3 variants (MAF $\leq 0.001)$ with susceptibility to UIA/aSAH, we compared the numbers of individuals carrying at least one missense variant in this gene among the 73 index case subjects in the present study (3/73 carrier; $4.11 \%$ ) versus 100 healthy/control individuals with North German ancestry (Hamburg controls: 0/100 carrier; 0.0\%) by gene burden and Sequence Kernel Association Tests (SKAT) [27]. We found a significant enrichment in individuals carrying EDIL3 missense variants with an MAF below $0.001(0.1 \%)$ in our study cohort versus healthy/control individuals (SKAT, $p=0.0298$; burden test, $p=0.0152$; Table S5). We obtained even stronger results when comparing allele counts among the 73 index case subjects versus 64,603 non-Finnish European individuals with exome/genome sequences derived from the gnomAD database v2 (326 variants in 64,603 individuals; SKAT, $p=2.53 \mathrm{e}-33$; burden test, $p=0.0000150$; Table S5) [24]. Finally, the cumulated allele frequency of very rare (allele frequencies $\leq 0.001)$ EDIL3 missense variants in non-finish Europeans listed in gnomAD $(326 / 64,603)$ is 0.00505 . Compared to this, the cumulative frequency of unknown/very rare variants (i.e. c. $383 \mathrm{G}>\mathrm{A}$ and c. $1159 \mathrm{~A}>\mathrm{C}$ ) in EDIL3 in our cohort $(3 / 73 ; 0.0411)$ is significantly higher (Fisher's exact $p=0.00624$; Table S5).

We explored the structural impacts of the p.(Cys128Tyr) and p.(Lys387Gln) changes using a model for EDIL3 EGFlike domains and discoidin domains, respectively [28, 29]. Molecular replacement of the amino acid $\mathrm{Cys}^{128}$ for a tyrosine resulted in (i) loss of the disulfide bridge between amino acid 128 and Cys ${ }^{143}$, and (ii) aberrant intramolecular interactions of $\mathrm{Tyr}^{128}$ with cysteines 143,145 and 154
(Fig. 1c). Replacement of the amino acid Lys ${ }^{387}$ for a glutamine resulted in loss of six intramolecular contacts with $\mathrm{Tyr}^{452}$ (Fig. 1c). These data suggest that both p.(Cys128Tyr) and p.(Lys387Gln) induce structural alterations which likely interfere with EDIL3 function.

Taken together, we identified two different EDIL3 missense variants, c. $383 \mathrm{G}>\mathrm{A}$ p.(Cys128Tyr) and c.1159A $>$ C p.(Lys387Gln), in three affected individuals from one family and in two unrelated patients, respectively. The p.(Cys128Tyr) variant is absent from databases, the p.(Lys387Gln) variant is very rare; this supports the hypothesis that the two variants might be involved in the pathogenesis of the disease. Both alterations are predicted to be damaging by combinational pathogenicity predictors as well as by molecular replacement, and the functional relevance of EDIL3 for vascular biology is strong (see "Discussion" section). Therefore, EDIL3 is a valid candidate disease gene for UIA/aSAH.

\section{Discussion}

\section{Phenotypic aspects}

For establishing our study cohort, we focused on patients with a severe clinical phenotype, a family history of UIA and/or SAH and few or no exogenous risk factors $[9,10]$. This resulted in a relatively young cohort consisting of patients with proven aSAH or a high number of UIA. As a clinical tool, the PHASES score assists physicians to assess the risk of aneurysm rupture; however, this score does not consider family history and genetic factors. Notably, the scores in our aSAH- and UIA-groups were similar and moderately high. This indicates a moderate sensitivity in a selected cohort of strongly affected patients with a high percentage of positive family history. Thus, incorporating genetic/familial aspects might improve the sensitivity of PHASES scoring system. We found EDIL3 variants in strongly affected patients with up to six IA. The two sporadic patients had no familial history and few exogenous risk factors for IA formation. One of these patients was diagnosed with three additional extracranial aneurysms and died subsequent to aortic surgery. The co-occurrence of intracranial and extracranial aneurysms in subject IA10 may suggest an overlapping pathogenesis of intracranial and extracranial vascular diseases, as already reported by others [30, 31], and may reflect the general importance of EDIL3 for vascular integrity.

\section{Validation of reported risk genes}

Continual evaluation of putative risk genes and refinement of reported risk alleles is essential for shaping the genetic 


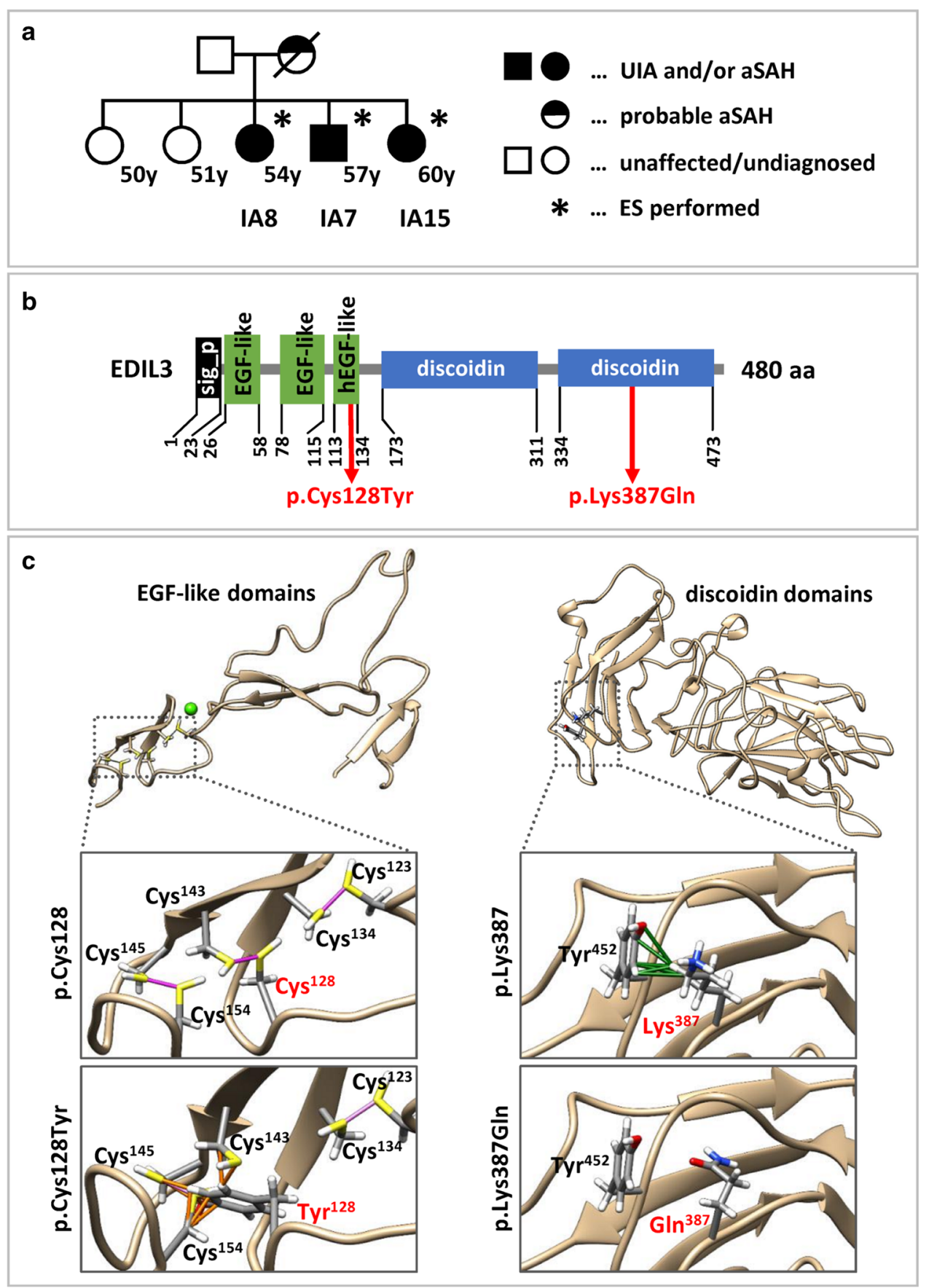

etiology of UIA/aSAH $[9,10]$. We examined reported risk genes ADAMTS15, ANGPTL6, ARHGEF17, LOXL2, PCNT, RNF213, THSD1 and TMEM132B via exome sequencing in 38 individuals with UIA/aSAH and identified variants with $\mathrm{MAF} \leq 0.05(5 \%)$ in 18 of them. Previously, four rare missense variants in PCNT exon 38 encoding a coiled coil motif have been identified in affected members of 2 different families and in 3 out of 161 unrelated patients with nontraumatic SAH or UIA (Figure S2A); thus a specific role for this domain in the etiology of IA/SAH has been suggested
[8]. We identified PCNT variants in 9 patients, which do not cluster in a specific region of the gene (Figure S2A). Two of these variants were predicted to alter splicing, three of these variants are likely benign (Table 2). Neither previously reported $P C N T$ missense variants nor those identified in our study localize within a constrained coding region [8, 32]. $P C N T$ is a highly mutable gene which is reflected by a very low misZ score (Table 2) [24]. Taken together, PCNT remains a good candidate gene for IA/SAH, however, final verification of $P C N T$ as a risk gene is still pending. Variants 
\Fig. 1 Pedigree for the affected family used for ES, domain structure of EDIL3 and structural impact of EDIL3 amino acid changes. a Pedigree. Exome sequenced individuals are marked with an asterisk. Criteria for defining the disease phenotypes (UIA and/or aSAH, probable aSAH) are outlined in the methods section. Age at inclusion is given in years (y). b Domain structure of EDIL3 comprising a signal peptide (sig_p, black), three (h)EGF-like domains (green) and 2 discoidin-like domains (blue) is shown relative to the size of the fulllength protein. Localization of amino acid changes p.(Cys128Tyr) and p.(Lys387Gln) is indicated. aa, amino acid. c Structural impact of EDIL3 p.Cys128Tyr and p.Lys387Gln amino acid changes. Amino acids 128 and 387 and surrounding residues are shown as sticks; side chains are colored by element (hydrogen: white; carbon: grey; oxygen: red; nitrogen: blue; cysteine: yellow). Left column: (h)EGF-like domains of EDIL3 and the structural environment of Cys ${ }^{128}$. Ribbon representations show details of the hEGF-like domain with conserved cysteines that form three and two disulfide bridges (magenta lines) for wild-type (p.Cys128, top) and mutated (p.Cys128Tyr, bottom) EDIL3, respectively. In silico substitution of Cys ${ }^{128}$ for tyrosine resulted in loss of the disulfide bridge with $\mathrm{Cys}^{143}$ and overlaps of atomic Van-der Waals (VDW) spheres (orange lines) between $\mathrm{Tyr}^{128}$ with cysteines 143, 145 and 154 indicating possible non-covalent clashes. Right column: Discoidin domains of EDIL3 and the structural environment of $\mathrm{Lys}^{387}$. Ribbon representations show details of the discoidin domain for wild-type (p.Lys387, top) and mutated (p.Lys387Gln, bottom) EDIL3. For Lys ${ }^{387}$ six VDW contacts with carbons, a nitrogen and a hydrogen of the $\mathrm{Tyr}^{452}$ were identified. In silico substitution of Lys ${ }^{387}$ for glutamine resulted in loss of all VDW contacts with $\mathrm{Tyr}^{452}$. New VDW contacts or overlaps of $\mathrm{Glu}^{387}$ with adjacent residues were not predicted

in $R N F 213$ predispose to Moyamoya disease in diverse ethnicities [33,34], and rare variants have been recently identified in 25 from 249 patients with IA/SAH in a French Canadian population [4]. Moreover, functional and genetic data strongly support that $R N F$ variants are associated with a variety of vascular disorders, as it has been discussed by Zhou et al. (2018) [4]. It was suggested that RNF213 exon 29 encoding AAA + ATPase domains might be the risk region for IA/SAH (Figure S2B) [4]. We identified four VUS in three patients with IA/SAH; one patient with a giant IA carries two rare $R N F 213$ variants (Table 2), and the variant c. $8084 \mathrm{C}>\mathrm{T}$ p.(Ala2695Val) in IA61 localizes in the linker region between the two AAA + domains (Figure S3). Moreover, we found a further VUS in RNF213 (c.10450G $>$ A p.(Gly3484Ser)) in two siblings with SAH but no detectable IAs (Supplementary Results, Table S6 and Figure S1B). Taken together, the plurality of independent evidences and $R N F 213$ intolerance of variation $(\mathrm{misZ}=2.3$ ) indicate that RNF 213 sequence alterations are risk factors for IA/SAH and related disorders. Genetic evidence suggested a role of THSDI variants in the pathogenesis of IA/SAH, previously, and missense variants identified in affected individuals clustered in the intracellular protein portion (Figure S2C) [5]. We observed two and one variants in the extracellular and intracellular THSD1 protein portion, respectively (Figure S2C). The THSD1 c.871C $>$ T p.(Glu291Lys) variant, which has a relatively high MAF (0.01864) was found in four unrelated individuals and it co-segregated with the disease in the family of IA90 (Figure S1A). Taken together, our data do not oppose but rather support a role of TSHD variation in the etiology of IA/SAH. For the discussion on variants in ANGPTL6, ADAMTS15, TMEM132B, ARHGEF17 and LOXL2 see Supplementary Discussion; overall evidence for an overlap of our data with previous studies on these five genes is very limited [this study, 6, 7, 9-11].

\section{Genetic and functional aspects on EDIL3 as an UIA/ aSAH risk gene}

There is no significant overlap in putative susceptibility genes between various ES-based studies [35], which may reflect a pronounced heterogeneity of IA/SAH pathogenesis. We also aimed to identify genetic risk factors for UIA/aSAH by a family-based ES approach, and we propose EDIL3 as new risk gene. From the genetic perspective, EDIL 3 is a very good candidate disease gene for UIA and aSAH because we identified likely deleterious variants in affected relatives in a family (Fig. 1a) and, additionally, in two unrelated individuals with UIA/aSAH. Moreover, association tests showed a statistically significant gene burden for EDIL3. Functional assessment of EDIL3 protein and the predicted amino acid substitutions (p.(Cys128Tyr), p.(Lys387Gln)) strongly supports this hypothesis (Supplementary Methods, Tables S3 and S4): The mouse homologue Edil3 was identified as a matrix-associated matricellular protein expressed by endothelial cells during embryonic vascular development [36]. Through its interaction with integrin receptors, Edil3 promotes adhesion of endothelial and vascular smooth muscle cells $[36,37]$. Both cell types are crucial for wall integrity of blood vessels and angiogenesis [38]. Edil3 is regulated by hypoxia or vascular injury and has been implicated in vascular remodeling during angiogenesis [39-41]. EDIL3 is highly expressed in blood vessels and in brain (Figure S3). Summarized, EDIL3 belongs to a number of epidermal growth factor (EGF) repeat containing genes in the vascular wall, which are essential for wall integrity and remodeling [37]. Amino acid changes p.(Cys128Tyr) and p.(Lys387Gln) affect highly conserved domains. EDIL3 has 3 N-terminal EGF-like domains, followed by two discoidin domains (Fig. 1b) [36]. The EGF modules are stabilized by six conserved cysteines forming 3 disulfide bonds in the pattern of 1-3, 2-4, and 5-6 (Fig. 1c) [28]. The p.(Cys128Tyr) change affects the 2 nd Cysteine in the 3rd calcium-binding EGF-like domain, which likely compromises the shape and function of the small domain (Fig. 1c). Accordingly, mutations of highly conserved cysteines in calcium-binding EGFlike domains play a seminal role in several diseases such as the Marfan syndrome [42]. The p.(Lys387Gln) change alters the 2nd discoidin domain (Fig. 1c), a structural entity that is found in many extracellular and membrane proteins 
Table 3 Top ranked putative pathogenic variants shared by three affected siblings

\begin{tabular}{|c|c|c|c|c|c|c|c|}
\hline \multirow{2}{*}{$\begin{array}{l}\text { Gene } \\
\text { gnomAD } \\
\text { constraint } \\
\text { metrics }\end{array}$} & \multirow[t]{2}{*}{ Transcript ID } & \multirow{2}{*}{$\begin{array}{l}\text { c. notation } \\
\text { p. notation }\end{array}$} & \multirow[t]{2}{*}{ Classification $^{\mathrm{a}}$} & \multirow{2}{*}{$\begin{array}{l}\text { Phenotype; } \\
\text { MIM number; } \\
\text { inheritance }\end{array}$} & \multicolumn{2}{|l|}{ Pathogenicity predictions ${ }^{\mathrm{b}}$} & \multirow{2}{*}{$\begin{array}{l}\text { Subjects: } \\
\text { clinical find- } \\
\text { ings }\end{array}$} \\
\hline & & & & & $\begin{array}{l}\text { CADD/REVEL/M- } \\
\text { CAP/ClinPred }\end{array}$ & $\begin{array}{l}\text { Impact on } \\
\text { splicing }\end{array}$ & \\
\hline $\begin{array}{l}N E K 4 \\
\text { misZ }=0.88 \\
\text { pLI }=0.0\end{array}$ & NM_003157 & $\begin{array}{l}\text { c. } 190 \mathrm{~A}>\mathrm{T} \\
\text { p.Asn64Tyr }\end{array}$ & $\mathrm{VUS}_{\mathrm{PM} 1+\mathrm{PM} 2+\mathrm{PP} 3}$ & n.r & 23.7/0.452/0.113/0.984 & n.d & $\begin{array}{l}\text { IA7: } 2 \text { IA } \\
\text { IA8: } 1 \text { IA + } 1 \\
\text { aSAH }\end{array}$ \\
\hline $\begin{array}{l}E D I L 3 \\
\text { misZ }=1.16 \\
\mathrm{pLI}=0.0\end{array}$ & NM_005711 & $\begin{array}{l}\text { c. } 383 \mathrm{G}>\mathrm{A} \\
\text { p.Cys128Tyr }\end{array}$ & $\mathrm{VUS}_{\mathrm{PM} 1+\mathrm{PM} 2+\mathrm{PP} 3}$ & n.r & 29.1/0.946/0.523/0.998 & n.d & IA15: 6 IA \\
\hline $\begin{array}{l}E D N R B \\
\text { misZ }=1.18 \\
\text { pLI }=0.01\end{array}$ & NM_001201397 & $\begin{array}{l}\text { c. } 891 \mathrm{~T}>\mathrm{G} \\
\text { p.Ser297Arg }\end{array}$ & VUS $_{\mathrm{PM} 2}$ & $\begin{array}{l}\text { Waardenburg } \\
\text { syndrome, } \\
\text { type 4A; } \\
\text { 277580; } \\
\text { AD, AR; } \\
\text { ABCD } \\
\text { syndrome, } \\
\text { 600501, AR; } \\
\text { Hirschsprung } \\
\text { disease, } \\
\text { susceptibil- } \\
\text { ity to, 2, } \\
\text { 600155, AD }\end{array}$ & 23.7/0.303/0.020/0.972 & $\begin{array}{l}\text { Gain of ESS } \\
\text { site (HSF); } \\
\text { no impact } \\
\text { (NG2, } \\
\text { MES) }\end{array}$ & \\
\hline $\begin{array}{l}\text { DNAH9 } \\
\text { misZ }=-0.04 \\
\mathrm{pLI}=0.0\end{array}$ & NM_001372 & $\begin{array}{l}\text { c. } 13304 \mathrm{~T}>\mathrm{C} \\
\text { p.Ile4435Thr }\end{array}$ & $\mathrm{VUS}_{\mathrm{PM} 2}$ & $\begin{array}{l}\text { Ciliary } \\
\text { dyskinesia, } \\
\text { primary, 40; } \\
\text { 618300; AR }\end{array}$ & $\mathbf{2 4 . 5} / 0.203 / 0.010 / \mathbf{0 . 9 8 3}$ & n.d & \\
\hline $\begin{array}{l}G G A 3 \\
\operatorname{misZ}=-0.01 \\
\mathrm{pLI}=0.0\end{array}$ & NM_138619 & $\begin{array}{l}\text { c. } 16 \mathrm{G}>\mathrm{A} \\
\text { p.Gly6Arg }\end{array}$ & $\mathrm{VUS}_{\mathrm{PM} 2+\mathrm{PP} 3}$ & n.r & 33.0/0.299/0.049/0.988 & n.d & \\
\hline
\end{tabular}

Sequence alterations were identified by filtering the exome sequencing data as described in the text. gnomAD constraint metrics (v2.1.1) including missense $Z$ score (misZ; intolerance to variation) and pLI score (probability of loss-of-function intolerance) are given. Transcript IDs correspond to the NCBI Reference Sequence (RefSeq) project. Nucleotide and amino acid changes are given according to the indicated transcript ID. Nucleotide numbering uses +1 as the A of the ATG translation initiation codon in the reference sequence, with the initiation codon as codon 1

$A D$ autosomal dominant, $A R$ autosomal recessive, ESS Exonic Splicing Silencer, $a S A H$ aneurysmal subarachnoid hemorrhage, $I A$ intracranial aneurysm (including unruptured and ruptured IA), MIM Mendelian inheritance in man, $n . d$. not determined, n.r. none reported

${ }^{a}$ Variant classification: VUS, variant of uncertain significance; classification criteria PM1, PM2, PP3 and BP4 are explained in the Supplementary Methods. PM1 was assigned to the NEK4 p.Asn64Tyr variant, because of the critical position in the so-called tyrosine-down motif (references see Supplementary Information). PM1 was assigned to the EDIL3 p.Cys128Tyr variant, because of its critical position in an EGF-like domain (see "Discussion")

${ }^{b}$ Details on pathogenicity predictors and respective thresholds [CADD $(\geq 20)$, REVEL $(\geq 0.5)$, M-CAP $(\geq 0.025)$, ClinPred ( $\left.\geq 0.5\right)$ ] as well as on splice site predictions with HSF, NetGene2 (NG2), MaxEntScan (MES) and BDGP are given in the Supplementary Methods. Scores $\geq$ thresholds are shown in bold numbers

involved in cellular adhesion, migration, or aggregation events, and associated with organogenesis (vasculogenesis and angiogenesis) [43]. The exact role of Lysine 387 that lies within a $\beta$-sheet of the discoidin domain has not yet been documented, however modelling of p.Lys387Gln suggested strong effects on the domain structure (Fig. 1c). Notably, it has been shown that depletion of EDIL 3 disrupts TGF $\beta$ signaling pathways [44]. Dysregulation of this signaling pathway is widely accepted to be central in the pathogenesis of hereditary aortopathies [45]. Numerous familial linkage and GWAS reporting on potential gene loci for IAs have been summarized elsewhere [18, 21]. A genome-wide-linkage/ haplotype-association analysis revealed a strong evidence for a linkage of IAs to the chromosomal region 5q14.3 with a p value of 0.001 for marker D5S428; this DNA marker localizes ca. $1 \mathrm{Mb}$ distal from EDIL3 [46].

\section{Conclusions}

ES studies in multiplex families produce reasonable candidate disease genes for UIA/aSAH. To validate or discard putative disease genes, large cohorts of UIA/aSAH families and sporadic patients are needed for future next-generation 
sequencing studies; thus, collaboration between research groups with substantial cohorts of patients will be essential. Based on the premise that there is pathophysiological overlap, ES data of individuals with other vascular diseases such as thoracic/abdominal aortic aneurysm could also be included. Definitive identification of genetic risk factors is highly desirable, as it will contribute to develop future tests to assess the risk of SAH in a routine clinical setting.

Acknowledgements Open Access funding provided by Projekt DEAL. We are grateful to the patients and their families who contributed to this study. We thank Inka Jantke for skillful technical assistance and Julia Butter for validation of exome data and performing sequencing analysis. We appreciate the constructive cooperation with the Department of Neuroradiological diagnostics and intervention and thank our colleagues for helping with patient recruitment. This work was supported by grants from the Deutsche Forschungsgemeinschaft (GR 3660/3-1 to G.R.) and from the Faculty of Medicine of the University Medical Center Hamburg-Eppendorf (FFM program "Project funding for young scientists" NWF-17/08 to T.S.).

Author contributions TS supervised the study, conceived the study question, collected clinical data, designed the analysis plan, analyzed and interpreted the sequencing data, and drafted the manuscript. SR contributed to data acquisition, analyzed and interpreted sequencing data, created molecular models and drafted the manuscript. MA and MS established the bioinformatics analysis pipeline and were responsible for the integrity and accuracy of the sequence data analysis. LK performed statistical analyses and association tests. AB processed the blood samples, extracted DNA, and performed Sanger sequencing. VK processed the blood samples, extracted DNA, performed Sanger sequencing, and took care of bio banking. JA processed DNA samples for ES and generated raw ES data. CB recruited control individuals and collected blood samples. B-SL, AF and WL processed and provided exome data from the IKMB (Institute of Clinical Molecular Biology, Kiel) in-house dataset (IKMB-controls) and the PopGen database [25, 26]. MW supervised collection of the clinical data and helped to conceive the study questions. NOS collected clinical data and helped to conceive the study questions. JR contributed to the overall design of the study and helped to conceive the study questions. GR supervised the study and conceived the study question, designed the analysis plan, analyzed and interpreted the sequencing data, drafted the manuscript, and is responsible for the manuscript as a whole.

\section{Compliance with ethical standards}

Conflicts of interest The authors declare that they have no conflict of interest.

Ethical standards The study was approved by the ethics committees of the Medical Chamber Hamburg (vote no. PV5082). Clinical data and samples were obtained with informed consent of the patients according to GCP regulations, the Declaration of Helsinki and the national legal regulations (i.e., the German Genetic Diagnosis Act (GenDG)).

Open Access This article is licensed under a Creative Commons Attribution 4.0 International License, which permits use, sharing, adaptation, distribution and reproduction in any medium or format, as long as you give appropriate credit to the original author(s) and the source, provide a link to the Creative Commons licence, and indicate if changes were made. The images or other third party material in this article are included in the article's Creative Commons licence, unless indicated otherwise in a credit line to the material. If material is not included in the article's Creative Commons licence and your intended use is not permitted by statutory regulation or exceeds the permitted use, you will need to obtain permission directly from the copyright holder. To view a copy of this licence, visit http://creativecommons.org/licenses/by/4.0/.

\section{References}

1. Feigin VL, Lawes CM, Bennett DA, Barker-Collo SL, Parag V (2009) Worldwide stroke incidence and early case fatality reported in 56 population-based studies: a systematic review. Lancet Neurol 8(4):355-369. https://doi.org/10.1016/S1474-4422(09)70025 $-0$

2. Vlak MH, Algra A, Brandenburg R, Rinkel GJ (2011) Prevalence of unruptured intracranial aneurysms, with emphasis on sex, age, comorbidity, country, and time period: a systematic review and meta-analysis. Lancet Neurol 10(7):626-636. https://doi. org/10.1016/S1474-4422(11)70109-0

3. Zhou S, Gan-Or Z, Ambalavanan A, Lai D, Xie P, Bourassa CV, Strong S, Ross JP, Dionne-Laporte A, Spiegelman D, Dupre N, Foroud TM, Xiong L, Dion PA, Rouleau GA (2018) Genomewide association analysis identifies new candidate risk loci for familial intracranial aneurysm in the French-Canadian population. Sci Rep 8(1):4356. https://doi.org/10.1038/s41598-018-21603-7

4. Zhou S, Ambalavanan A, Rochefort D, Xie P, Bourassa CV, Hince P, Dionne-Laporte A, Spiegelman D, Gan-Or Z, Mirarchi C, Zaharieva V, Dupre N, Kobayashi H, Hitomi T, Harada K, Koizumi A, Xiong L, Dion PA, Rouleau GA (2016) RNF213 is associated with intracranial aneurysms in the French-Canadian population. Am J Hum Genet 99(5):1072-1085. https://doi.org/10.1016/j. ajhg.2016.09.001

5. Santiago-Sim T, Fang X, Hennessy ML, Nalbach SV, DePalma SR, Lee MS, Greenway SC, McDonough B, Hergenroeder GW, Patek KJ, Colosimo SM, Qualmann KJ, Hagan JP, Milewicz DM, MacRae CA, Dymecki SM, Seidman CE, Seidman JG, Kim DH (2016) THSD1 (thrombospondin type 1 domain containing protein 1) mutation in the pathogenesis of intracranial aneurysm and subarachnoid hemorrhage. Stroke 47(12):3005-3013. https://doi. org/10.1161/STROKEAHA.116.014161

6. Bourcier R, Le Scouarnec S, Bonnaud S, Karakachoff M, Bourcereau E, Heurtebise-Chretien S, Menguy C, Dina C, Simonet F, Moles A, Lenoble C, Lindenbaum P, Chatel S, Isidor B, Genin E, Deleuze JF, Schott JJ, Le Marec H, Group IS, Loirand G, Desal H, Redon R (2018) Rare coding variants in ANGPTL6 are associated with familial forms of intracranial aneurysm. Am J Hum Genet 102(1):133-141. https://doi.org/10.1016/j. ajhg.2017.12.006

7. Yang X, Li J, Fang Y, Zhang Z, Jin D, Chen X, Zhao Y, Li M, Huan L, Kent TA, Dong JF, Jiang R, Yang S, Jin L, Zhang J, Zhong TP, Yu F (2018) Rho guanine nucleotide exchange factor ARHGEF17 is a risk gene for intracranial aneurysms. Circ Genom Precis Med 11(7):e002099. https://doi.org/10.1161/ CIRCGEN.117.002099

8. Lorenzo-Betancor O, Blackburn PR, Edwards E, Vazquez-doCampo R, Klee EW, Labbe C, Hodges K, Glover P, Sigafoos AN, Soto AI, Walton RL, Doxsey S, Bober MB, Jennings S, Clark KJ, Asmann Y, Miller D, Freeman WD, Meschia J, Ross OA (2018) PCNT point mutations and familial intracranial aneurysms. Neurology 91(23):e2170-e2181. https://doi.org/10.1212/WNL.00000 00000006614

9. Farlow JL, Lin H, Sauerbeck L, Lai D, Koller DL, Pugh E, Hetrick K, Ling H, Kleinloog R, van der Vlies P, Deelen P, Swertz MA, Verweij BH, Regli L, Rinkel GJ, Ruigrok YM, Doheny K, Liu Y, Broderick J, Foroud T, Investigators FIAS (2015) Lessons learned 
from whole exome sequencing in multiplex families affected by a complex genetic disorder, intracranial aneurysm. PLoS ONE 10(3):e0121104. https://doi.org/10.1371/journal.pone.0121104

10. Yan J, Hitomi T, Takenaka K, Kato M, Kobayashi H, Okuda H, Harada KH, Koizumi A (2015) Genetic study of intracranial aneurysms. Stroke 46(3):620-626. https://doi.org/10.1161/STROK EAHA.114.007286

11. Wu Y, Li Z, Shi Y, Chen L, Tan H, Wang Z, Yin C, Liu L, Hu J (2018) Exome sequencing identifies LOXL2 mutation as a cause of familial intracranial aneurysm. World Neurosurg 109:e812e818. https://doi.org/10.1016/j.wneu.2017.10.094

12. Tromp G, Weinsheimer S, Ronkainen A, Kuivaniemi H (2014) Molecular basis and genetic predisposition to intracranial aneurysm. Ann Med 46(8):597-606. https://doi.org/10.3109/07853 890.2014.949299

13. Bor AS, Rinkel GJ, Adami J, Koffijberg H, Ekbom A, Buskens E, Blomqvist P, Granath F (2008) Risk of subarachnoid haemorrhage according to number of affected relatives: a population based case-control study. Brain 131(Pt 10):2662-2665. https:// doi.org/10.1093/brain/awn187

14. Korja M, Silventoinen K, McCarron P, Zdravkovic S, Skytthe A, Haapanen A, de Faire U, Pedersen NL, Christensen K, Koskenvuo M, Kaprio J, Genom EP (2010) Genetic epidemiology of spontaneous subarachnoid hemorrhage: Nordic Twin Study. Stroke 41(11):2458-2462. https://doi.org/10.1161/STROK EAHA. 110.586420

15. The_ACROSS_Group (2000) Epidemiology of aneurysmal subarachnoid hemorrhage in Australia and New Zealand: incidence and case fatality from the Australasian Cooperative Research on Subarachnoid Hemorrhage Study (ACROSS). Stroke 31(8):1843-1850

16. Wermer MJ, Greebe P, Algra A, Rinkel GJ (2005) Incidence of recurrent subarachnoid hemorrhage after clipping for ruptured intracranial aneurysms. Stroke 36(11):2394-2399. https://doi. org/10.1161/01.STR.0000185686.28035.d2

17. Greving JP, Wermer MJ, Brown RD Jr, Morita A, Juvela S, Yonekura M, Ishibashi T, Torner JC, Nakayama T, Rinkel GJ, Algra A (2014) Development of the PHASES score for prediction of risk of rupture of intracranial aneurysms: a pooled analysis of six prospective cohort studies. Lancet Neurol 13(1):59-66. https ://doi.org/10.1016/S1474-4422(13)70263-1

18. Zhou S, Dion PA, Rouleau GA (2018) Genetics of intracranial aneurysms. Stroke 49(3):780-787. https://doi.org/10.1161/ STROKEAHA.117.018152

19. Whiffin N, Minikel E, Walsh R, O'Donnell-Luria AH, Karczewski K, Ing AY, Barton PJR, Funke B, Cook SA, MacArthur D, Ware JS (2017) Using high-resolution variant frequencies to empower clinical genome interpretation. Genet Med 19(10):1151-1158. https://doi.org/10.1038/gim.2017.26

20. Gibson G (2012) Rare and common variants: twenty arguments. Nat Rev Genet 13(2):135-145. https://doi.org/10.1038/nrg3118

21. Hitchcock E, Gibson WT (2017) A review of the genetics of intracranial berry aneurysms and implications for genetic counseling. J Genet Couns 26(1):21-31. https://doi.org/10.1007/s1089 7-016-0029-8

22. Bomba L, Walter K, Soranzo N (2017) The impact of rare and low-frequency genetic variants in common disease. Genome Biol 18(1):77. https://doi.org/10.1186/s13059-017-1212-4

23. Richards S, Aziz N, Bale S, Bick D, Das S, Gastier-Foster J, Grody WW, Hegde M, Lyon E, Spector E, Voelkerding K, Rehm HL, Committee ALQA (2015) Standards and guidelines for the interpretation of sequence variants: a joint consensus recommendation of the American College of Medical Genetics and Genomics and the Association for Molecular Pathology. Genet Med 17(5):405-424. https://doi.org/10.1038/gim.2015.30
24. Lek M, Karczewski KJ, Minikel EV, Samocha KE, Banks E, Fennell T, O'Donnell-Luria AH, Ware JS, Hill AJ, Cummings BB, Tukiainen T, Birnbaum DP, Kosmicki JA, Duncan LE, Estrada K, Zhao F, Zou J, Pierce-Hoffman E, Berghout J, Cooper DN, Deflaux N, DePristo M, Do R, Flannick J, Fromer M, Gauthier L, Goldstein J, Gupta N, Howrigan D, Kiezun A, Kurki MI, Moonshine AL, Natarajan P, Orozco L, Peloso GM, Poplin R, Rivas MA, Ruano-Rubio V, Rose SA, Ruderfer DM, Shakir K, Stenson PD, Stevens C, Thomas BP, Tiao G, Tusie-Luna MT, Weisburd B, Won HH, Yu D, Altshuler DM, Ardissino D, Boehnke M, Danesh J, Donnelly S, Elosua R, Florez JC, Gabriel SB, Getz G, Glatt SJ, Hultman CM, Kathiresan S, Laakso M, McCarroll S, McCarthy MI, McGovern D, McPherson R, Neale BM, Palotie A, Purcell SM, Saleheen D, Scharf JM, Sklar P, Sullivan PF, Tuomilehto J, Tsuang MT, Watkins HC, Wilson JG, Daly MJ, MacArthur DG, Exome Aggregation C (2016) Analysis of protein-coding genetic variation in 60,706 humans. Nature 536(7616):285-291. https:// doi.org/10.1038/nature19057

25. Krawczak M, Nikolaus S, von Eberstein H, Croucher PJ, El Mokhtari NE, Schreiber S (2006) PopGen: population-based recruitment of patients and controls for the analysis of complex genotype-phenotype relationships. Community Genet 9(1):55-61. https://doi.org/10.1159/000090694

26. Lieb W, Jacobs G, Wolf A, Richter G, Gaede KI, Schwarz J, Arnold N, Bohm R, Buyx A, Cascorbi I, Franke A, Glinicke C, Held-Feindt J, Junker R, Kalthoff H, Kramer HH, Leypoldt F, Maass N, Maetzler W, May S, Mehdorn HM, Rocken C, Schafmayer C, Schrappe M, Schreiber S, Sebens S, Stephani U, Synowitz M, Weimer J, Zabel P, Nothlings U, Roder C, Krawczak M (2019) Linking pre-existing biorepositories for medical research: the PopGen 2.0 Network. J Community Genet 10(4):523-530. https://doi.org/10.1007/s12687-019-00417-8

27. Lee S, Emond MJ, Bamshad MJ, Barnes KC, Rieder MJ, Nickerson DA, Team NGESP-ELP, Christiani DC, Wurfel MM, Lin X (2012) Optimal unified approach for rare-variant association testing with application to small-sample case-control whole-exome sequencing studies. Am J Hum Genet 91(2):224-237. https://doi. org/10.1016/j.ajhg.2012.06.007

28. Schurpf T, Chen Q, Liu JH, Wang R, Springer TA, Wang JH (2012) The RGD finger of Del-1 is a unique structural feature critical for integrin binding. FASEB J 26(8):3412-3420. https:// doi.org/10.1096/fj.11-202036

29. Carafoli F, Mayer MC, Shiraishi K, Pecheva MA, Chan LY, Nan R, Leitinger B, Hohenester E (2012) Structure of the discoidin domain receptor 1 extracellular region bound to an inhibitory Fab fragment reveals features important for signaling. Structure 20(4):688-697. https://doi.org/10.1016/j.str.2012.02.011

30. Rouchaud A, Brandt MD, Rydberg AM, Kadirvel R, Flemming K, Kallmes DF, Brinjikji W (2016) Prevalence of intracranial aneurysms in patients with aortic aneurysms. AJNR Am J Neuroradiol 37(9):1664-1668. https://doi.org/10.3174/ajnr.A4827

31. Jung WS, Kim JH, Ahn SJ, Song SW, Kim BM, Seo KD, Suh SH (2017) Prevalence of intracranial aneurysms in patients with aortic dissection. AJNR Am J Neuroradiol 38(11):2089-2093. https:// doi.org/10.3174/ajnr.A5359

32. Havrilla JM, Pedersen BS, Layer RM, Quinlan AR (2019) A map of constrained coding regions in the human genome. Nat Genet 51(1):88-95. https://doi.org/10.1038/s41588-018-0294-6

33. Cecchi AC, Guo D, Ren Z, Flynn K, Santos-Cortez RL, Leal SM, Wang GT, Regalado ES, Steinberg GK, Shendure J, Bamshad MJ, University of Washington Center for Mendelian G, Grotta JC, Nickerson DA, Pannu H, Milewicz DM (2014) RNF213 rare variants in an ethnically diverse population with Moyamoya disease. Stroke 45(11):3200-3207. https://doi.org/10.1161/STROK EAHA.114.006244 
34. Koizumi A, Kobayashi H, Hitomi T, Harada KH, Habu T, Youssefian S (2016) A new horizon of moyamoya disease and associated health risks explored through RNF213. Environ Health Prev Med 21(2):55-70. https://doi.org/10.1007/s12199-015-0498-7

35. Xu Z, Rui YN, Hagan JP, Kim DH (2019) Intracranial aneurysms: pathology, genetics, and molecular mechanisms. Neuromol Med. https://doi.org/10.1007/s12017-019-08537-7

36. Hidai C, Zupancic T, Penta K, Mikhail A, Kawana M, Quertermous EE, Aoka Y, Fukagawa M, Matsui Y, Platika D, Auerbach R, Hogan BL, Snodgrass R, Quertermous T (1998) Cloning and characterization of developmental endothelial locus-1: an embryonic endothelial cell protein that binds the alphavbeta3 integrin receptor. Genes Dev 12(1):21-33

37. Rezaee M, Penta K, Quertermous T (2002) Del1 mediates VSMC adhesion, migration, and proliferation through interaction with integrin alpha(v)beta(3). Am J Physiol Heart Circ Physiol 282(5):H1924-1932. https://doi.org/10.1152/ajpheart.00921.2001

38. Xu J, Shi GP (2014) Vascular wall extracellular matrix proteins and vascular diseases. Biochim Biophys Acta 1842(11):21062119. https://doi.org/10.1016/j.bbadis.2014.07.008

39. Zhong J, Eliceiri B, Stupack D, Penta K, Sakamoto G, Quertermous T, Coleman M, Boudreau N, Varner JA (2003) Neovascularization of ischemic tissues by gene delivery of the extracellular matrix protein Del-1. J Clin Investig 112(1):30-41. https://doi. org/10.1172/JCI17034

40. Aoka Y, Johnson FL, Penta K, Hirata Ki K, Hidai C, Schatzman R, Varner JA, Quertermous T (2002) The embryonic angiogenic factor Del1 accelerates tumor growth by enhancing vascular formation. Microvasc Res 64(1):148-161. https://doi.org/10.1006/ mvre.2002.2414

41. Kakino A, Fujita Y, Nakano A, Horiuchi S, Sawamura T (2016) Developmental endothelial locus-1 (Del-1) inhibits oxidized lowdensity lipoprotein activity by direct binding, and its overexpression attenuates atherogenesis in mice. Circ J 80(12):2541-2549. https://doi.org/10.1253/circj.CJ-16-0808

42. Handford P, Downing AK, Rao Z, Hewett DR, Sykes BC, Kielty CM (1995) The calcium binding properties and molecular organization of epidermal growth factor-like domains in human fibrillin-1. J Biol Chem 270(12):6751-6756

43. Kiedzierska A, Smietana K, Czepczynska H, Otlewski J (2007) Structural similarities and functional diversity of eukaryotic discoidin-like domains. Biochim Biophys Acta 1774(9):1069-1078. https://doi.org/10.1016/j.bbapap.2007.07.007

44. Zhang R, Wei YH, Zhao CY, Song HY, Shen N, Cui X, Gao X, Qi ZT, Zhong M, Shen W (2018) EDIL3 depletion suppress epithelial-mesenchymal transition of lens epithelial cells via transforming growth factor beta pathway. Int J Ophthalmol 11(1):18-24. https://doi.org/10.18240/ijo.2018.01.04

45. Cannaerts E, van de Beek G, Verstraeten A, Van Laer L, Loeys B (2015) TGF-beta signalopathies as a paradigm for translational medicine. Eur J Med Genet 58(12):695-703. https://doi. org/10.1016/j.ejmg.2015.10.010

46. Onda H, Kasuya H, Yoneyama T, Takakura K, Hori T, Takeda J, Nakajima T, Inoue I (2001) Genomewide-linkage and haplotype-association studies map intracranial aneurysm to chromosome 7q11. Am J Hum Genet 69(4):804-819. https://doi. org/10.1086/323614

\section{Affiliations}

\section{Thomas Sauvigny ${ }^{1}$ - Malik Alawi ${ }^{2}$. Linda Krause ${ }^{3} \cdot$ Sina Renner $^{4} \cdot$ Michael Spohn ${ }^{2,5,6}$. Alice Busch ${ }^{4}$. Verena Kolbe ${ }^{4}$. Janine Altmüller ${ }^{7}$. Britt-Sabina Löscher ${ }^{8}$. Andre Franke ${ }^{8}$. Christian Brockmann ${ }^{9} \cdot$ Wolfgang Lieb $^{10}$. Manfred Westphal ${ }^{1} \cdot$ Nils Ole Schmidt $^{1,11}$. Jan Regelsberger ${ }^{1} \cdot$ Georg Rosenberger $^{4}($ )}

1 Department of Neurosurgery, University Medical Center Hamburg-Eppendorf, Martinistraße 52, 20246 Hamburg, Germany

2 Bioinformatics Core, University Medical Center Hamburg-Eppendorf, Martinistraße 52, 20246 Hamburg, Germany

3 Institute of Medical Biometry and Epidemiology, University Medical Center Hamburg-Eppendorf, Martinistraße 52, 20246 Hamburg, Germany

4 Institute of Human Genetics, University Medical Center Hamburg-Eppendorf, Martinistraße 52, 20246 Hamburg, Germany

5 Research Institute Children's Cancer Center Hamburg, Martinistraße 52, 20251 Hamburg, Germany

6 Department of Oncology, Hematology and Bone Marrow Transplantation With Section Pneumology, Hubertus Wald Tumorzentrum, University Comprehensive Cancer Center Hamburg, University Medical Center Hamburg-Eppendorf, Martinistraße 52, 20246 Hamburg, Germany
7 Cologne Center for Genomics, Center for Molecular Medicine Cologne (CMMC), University of Cologne, Weyertal 115b, 50931 Cologne, Germany

8 Institute of Clinical Molecular Biology, Christian-Albrechts-University Kiel, Rosalind-Franklin-Straße 12, 24105 Kiel, Germany

9 Institute of Transfusion Medicine, University Hospital of Schleswig-Holstein, Campus Lübeck, Ratzeburger Allee 160, 23538 Lübeck, Germany

10 Institute of Epidemiology, Christian-Albrechts-University Kiel, Niemannsweg 11, 24105 Kiel, Germany

11 Department of Neurosurgery, University Medical Center Regensburg, Franz-Josef-Strauss-Allee 11, 93053 Regensburg, Germany 